\title{
Population genetic analysis and trichothecene profiling of Fusarium graminearum from wheat in Uruguay
}

\author{
D. Pan ${ }^{1}$, A. Mionetto', N. Calero', M.M. Reynoso ${ }^{2}$, A. Torres ${ }^{2}$ and L. Bettucci ${ }^{1}$ \\ 'Laboratorio de Micología, Facultad de Ciencias, Facultad de Ingeniería, UdelaR, \\ Montevideo, Uruguay \\ 2Departamento de Microbiología e Immunología, Facultad de Ciencias Exactas, \\ Físico Químicas y Naturales, Universidad Nacional de Río Cuarto, Córdoba, \\ Argentina
}

Corresponding author: D. Pan

E-mail: dpan@fing.edu.uy

Genet. Mol. Res. 15 (1): gmr.15017270

Received August 21, 2015

Accepted October 5, 2015

Published March 11, 2016

DOI http://dx.doi.org/10.4238/gmr.15017270

ABSTRACT. Fusarium graminearum sensu stricto (F. graminearum s.s.) is the major causal agent of Fusarium head blight of wheat worldwide, and contaminates grains with trichothecene mycotoxins that cause serious threats to food safety and animal health. An important aspect of managing this pathogen and reducing mycotoxin contamination of wheat is knowledge regarding its population genetics. Therefore, isolates of F. graminearum s.s. from the major wheat-growing region of Uruguay were analyzed by amplified fragment length polymorphism assays, PCR genotyping, and chemical analysis of trichothecene production. Of the 102 isolates identified as having the 15-ADON genotype via PCR genotyping, all were DON producers, but only 41 strains were also 15-ADON producers, as determined by chemical analysis. The populations were genotypically diverse but genetically similar, with significant genetic exchange occurring between them. Analysis of molecular variance indicated that most of the genetic variability resulted from differences between isolates within 
populations. Multilocus linkage disequilibrium analysis suggested that the isolates had a panmictic population genetic structure and that there is significant recombination occurs in F. graminearum s.s. In conclusion, tour findings provide the first detailed description of the genetic structure and trichothecene production of populations of $F$. graminearum s.s. from Uruguay, and expands our understanding of the agroecology of $F$. graminearum and of the correlation between genotypes and trichothecene chemotypes.

Key words: Fusarium graminearum; Wheat; Genetic structure; Trichothecene; Fusarium head blight

\section{INTRODUCTION}

Fusarium head blight (FHB) is economically one of the most devastating fungal diseases of wheat worldwide. The International Maize and Wheat Improvement Center has recognized FHB as a major factor limiting cereal production globally (Stack, 2000). In the last decade, FHB has caused destructive epidemics to wheat in Uruguay, causing yield losses of up to $60 \%$ and substantial decreases in prices due to reduced seed quality and mycotoxin contamination (Pan et al., 2009).

Members of the Fusarium graminearum species complex (FGSC) are the major causal agents of $\mathrm{FHB}$ of wheat worldwide, and consist of sixteen phylogenetically distinct species (Desjardins and Proctor, 2011). The most geographically widespread species of the FGSC is $F$. graminearum sensu stricto (F. graminearum s.s.), which predominantly affects wheat in North America, South America and Europe (Tóth et al., 2005; Ward et al., 2008; Astolfi et al., 2012; Somma et al., 2014; Aamot et al., 2015). A previous report showed that F. graminearum s.s. has been the dominant species affecting wheat in Uruguay, although Fusarium asiaticum was also found and was found to be associated with rice production (Umpiérrez-Failache et al., 2013). In addition to yield losses, a great concern is the ability of $F$. graminearum s.s. to contaminate grains with type B trichothecenes such as deoxynivalenol (DON), 3-acetyldeoxynivalenol (3-ADON), 15-acetyldeoxynivalenol (15-ADON), and nivalenol (NIV) along with its acetylated derivatives. These trichothecenes are sesquiterpenoids that are potent inhibitors of eukaryotic protein biosynthesis. Adverse effects of these toxins in human and animals include vomiting, feed refusal, diarrhea, emesis, and immunosuppression (Marasas et al., 1984). Additionally, the different trichothecene mycotoxins have different toxicological properties. For example, NIV is more toxic than DON to humans and domestic animals, and hence a stricter limit for the temporary tolerable daily intake of NIV than that of DON $(0.7 \mu \mathrm{g} / \mathrm{kg}$ body weight for NIV; $1 \mu \mathrm{g} / \mathrm{kg}$ for DON) has been issued by the European Scientific Committee for Food (van der Lee et al., 2015). In Uruguay, only DON levels have been regulated in wheat grains and their by-products for human consumption (MSP, 2001).

Strains of the FGSC usually synthesize one of the following three strain-specific profiles of trichothecene metabolites: DON and 3-ADON (3-ADON chemotype), DON and 15-ADON (15ADON chemotype), or NIV and its acetylated derivatives (NIV chemotype) (Ward et al., 2002). PCR-based assays have been developed for the rapid assessment of trichothecene genotypes of F. graminearum. Such assays rely on the amplification of gene regions that code for key enzymes involved in trichothecene biosynthesis (Ward et al., 2002; Quarta et al., 2006). Primers based on the sequences of genes Tri3, Tri5, and Tri7 have been designed to differentiate between the three toxin genotypes (3-ADON, 15-ADON, and NIV, respectively) (Quarta et al., 2006), and primers for Tri7 
and Tri13 have been used to distinguish between DON and NIV producers, respectively (Chandler et al., 2003). While trichothecene genotypes refer to PCR-based analyses of the Tri genes, chemotypes refer to chemical-based analyses (Desjardins, 2008). However, due to discrepancies between genotypes and chemical data reported previously, both types of analysis are necessary to define the profile of trichothecenes that $F$. graminearum isolates synthesize (Mugrabi de Kuppler et al., 2011; Castañares et al., 2014; Somma et al., 2014). Furthermore, chemical profile surveys of $F$. graminearum s.s. isolated from wheat have not been previously carried out in Uruguay.

An important aspect in managing this pathogen is knowledge regarding the genetic structure of $F$. graminearum populations. Understanding the genetic structure of this fungal pathogen population may provide insights into the epidemiology and evolutionary potential of $F$. graminearum and could lead to improved strategies to control it (Zeller et al., 2003). Moreover, an aincreased understanding of the genetic structure of plant pathogen populations is a prerequisite for developing innovative and rational approaches for plant disease management. In particular, the nature of the genetic diversity and gene flow patterns of plant pathogens and their association with phenotypic characters such as aggressiveness and mycotoxin production are useful for the development of durable resistance and management of fungicide resistance (Miedaner et al., 2008).

Studies on the genetic structure of $F$. graminearum populations have been done in different geographic regions including China (Qu et al., 2008), Nepal (Desjardins and Proctor, 2011), Europe (Tóth et al., 2005; Miedaner et al., 2008), North America (Guo et al., 2008; Ward et al., 2008), and South America (Ramírez et al., 2007; Astolfi et al., 2012). These studies have shown that there are high levels of genotypic diversity within F. graminearum populations, which suggests that recombination occurs regularly in these populations.

Based on these findings, we hypothesized that individual fungi within F. graminearum populations in Uruguay are genetically diverse and are part of a larger interconnected population that covers the entire major wheat-growing region. Additionally, we hypothesized that the trichothecene profile is similar to those found in other parts of the world, and that no potential shifts exist in the populations with respect to previous studies from Uruguay. Hence, the aims of this study were to define the genetic structure and to characterize the trichothecene production profiles of $F$. graminearum s.s. populations present in the major wheat-growing region of Uruguay.

\section{MATERIAL AND METHODS}

\section{Sampling}

The 93 fields sampled were within an area of $30,000 \mathrm{~km}^{2}$, and were located in the departments of Soriano, Río Negro, Colonia, and Flores (Figure 1). All fields were planted with the variety Baguette 9, which is highly susceptible to FHB. In each field, fifty wheat spikes were collected from $5 \times 5 \mathrm{~m}^{2}$ plot areas during the 2010 harvest season. Each spike was shelled by hand and the grains were pooled and stored at $-20^{\circ} \mathrm{C}$ in paper bags in the laboratory.

\section{Fusarium isolation}

Grains from each field were surface-disinfected by soaking in $1 \%$ aqueous $\mathrm{NaOCl}$ for 1 min, and then rinsed three times with sterile water. One hundred grains were plated (10 grains per Petri dish) on potato dextrose agar (PDA) containing $0.2 \mathrm{~g} / \mathrm{L}$ pentachloronitrobenzene. These plates were incubated at $24^{\circ} \mathrm{C}$ for 7 days under 12-h light/dark cycles. Single conidia of each Fusarium 
isolate were subcultured and then transferred to carnation leaf agar and PDA and incubated at $24^{\circ} \mathrm{C}$ for 7 days under 12-h light/dark cycles as previously described (Leslie and Summerell, 2006).

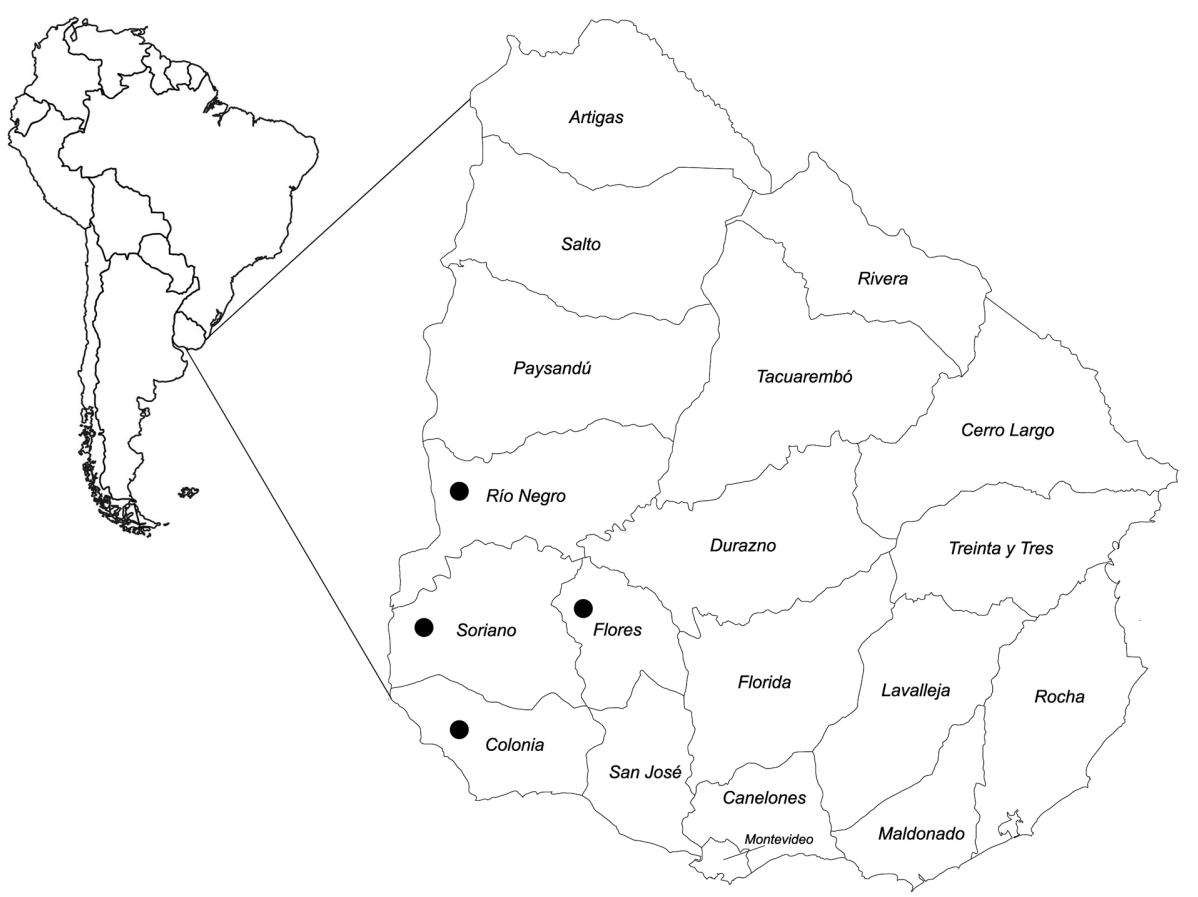

Figure 1. Sampling sites in the major wheat-growing region of Uruguay where wheat grains were obtained.

\section{DNA isolation}

Fungal DNA was extracted from aerial mycelium with a cetyltrimethylammonium bromide method following published procedures (Lee and Taylor, 1990).

\section{Amplified fragment length polymorphism (AFLP) reactions}

AFLP reactions were performed as described by Vos et al. (1995), and as modified by Leslie and Summerell (2006) in a PTC-2000 Thermal Cycler (MJ Research Inc., Watertown, MA, USA). All buffers and DNA-modifying enzymes were used following either manufacturer instructions or standard protocols (Green and Sambrook, 2012). Genomic DNA was digested to completion with EcoRI and $\mathrm{Msel}$ and ligated to AFLP adapters in a single overnight reaction at room temperature $\left(21^{\circ}-24^{\circ} \mathrm{C}\right)$, and then diluted in nine volumes of Tris-EDTA buffer prior to preamplification. The following three primer-pair combinations with two selective nucleotides on each primer were used: $E c o R I+A A$ and $M s e l+A T, E c o R I+C C$ and Msel $+C G$, and EcoRI + TG and Msel + TT. The EcoRI primer was labeled with $\left[\gamma-{ }^{33} \mathrm{P}\right]$ ATP for detection of bands by autoradiography. Polymorphic AFLP bands ranging from approximately 200 to $600 \mathrm{bp}$ in length were scored manually. Each band was treated as a distinct locus, with two alleles. All bands in this size range were scored, including those that were monomorphic. Bands migrating to the same position were assumed to be homologous 
and to represent the same allele and locus. Bands differing in mobility were treated as independent loci with two alleles. AFLP data were recorded in a binary format (allele present $=1$ or absent $=$ 0 ). Unresolved bands and missing data were treated as ambiguous data. Multiple runs of DNA from the same isolate were at least $98 \%$ similar, so a cut-off value of $98 \%$ similarity was used to identify clones. We included the following reference isolates identified as belonging to the FGS: Fusarium austroamericanum NRRL 2903 (lineage 1), Fusarium meridionale NRRL 28436 (lineage 2), Fusarium boothii NRRL 26916 (lineage 3), Fusarium mesoamericanum NRRL 25797 (lineage 4), Fusarium acaciae-mearnsii NRRL 26754 (lineage 5), Fusarium asiaticum NRRL 13818 (lineage 6), F. graminearum s.s. (lineage 7), Fusarium cortaderiae 29297 (lineage 8), Fusarium brasilicum NRRL 31281, Fusarium vorosii NRRL 37605, and Fusarium gerlachii NRRL36905 as standards on each gel (Desjardins and Proctor, 2011).

\section{Population genetic analyses}

We identified indistinguishable F. graminearum isolates, i.e., clones, as those isolates with AFLP haplotypes that shared $\geq 98 \%$ similarity as described above. The population was then clone-censored, i.e., only one strain of each clone was retained for analyses of genetic diversity and linkage disequilibrium. We estimated the allele frequencies of polymorphic loci and gene diversity $(h)$ within and between populations as described by Nei (1973); $G_{\mathrm{ST}}$ (fixation index) as described by Nei (1973); $N_{\mathrm{m}}$ (effective migration rate) as described by McDermontt and McDonald (1993); genetic identity among populations as described by Nei (1978); and two-locus linkage disequilibrium as described by Weir (1979) with the freeware program POPGENE version 1.32. All data analyzed with this program were treated as haploid with dominant markers. These analyses were done for a subset of data that included only those loci for which both alleles (presence or absence) were present at $\geq 5 \%$ frequency in at least one of the four populations. We also assessed two-locus linkage disequilibriums between all pairs of AFLP loci in each of the populations. The null hypothesis of linkage equilibrium was rejected in favor of the alternative hypothesis (linkage disequilibrium) at $\mathrm{P}<0.01$ and $\mathrm{P}<0.05$ for $\chi^{2}$ tests. The multilocus linkage disequilibrium (LD) for each of the four populations was calculated with MultiLocus version 1.3. We also estimated genotype diversity (G) for each population as described by Milgroom (1996), and the index of each population was normalized by dividing each estimated $\hat{G}$ by the number of genotypes identified from that population. Arlequin version 2.0 was used for analysis of molecular variance (AMOVA) to estimate variance among and within populations.

\section{Species detection using PCR specific assays}

DNA from all isolates was amplified by PCR with the $\mathrm{Fg} 16 \mathrm{~F} / \mathrm{R}$ primers, which produce polymorphic products (400-500 bp) with DNA from members of the FGSC as previously described (Nicholson et al., 1998).

\section{Trichothecene genotype determination}

Multiplex PCR assays were performed for the determination of trichothecene genotypes. PCR amplification reactions contained $25 \mathrm{ng}$ fungal DNA in a total volume of $50 \mu \mathrm{L} 1 \mathrm{X}$ reaction buffer containing $1.5 \mathrm{mM} \mathrm{MgCl}$; $5 \mathrm{U}$ Taq DNA polymerase (Promega); $200 \mathrm{mM}$ dNTPs; $0.2 \mathrm{mM}$ each of the Tri3 primers Tri3F971, Tri3F1325, and Tri3R1679; and 0.1 mM each of primers Tri7F340, 
Tri7R965, 3551H, and 4056H (Quarta et al., 2006). A negative control, containing all reagents and primers but no fungal DNA was included with every set of reactions. PCR was conducted in a PTC2000 Thermal Cycler (MJ Research Inc.). The PCR conditions were as follows: $94^{\circ} \mathrm{C}$ for 3 min; then 35 cycles of $94^{\circ} \mathrm{C}$ for $30 \mathrm{~s}, 53^{\circ} \mathrm{C}$ for $30 \mathrm{~s}$, and $72^{\circ} \mathrm{C}$ for $1 \mathrm{~min}$; followed by a final extension step of $72^{\circ} \mathrm{C}$ for $10 \mathrm{~min}$. PCR products were separated by electrophoresis with $2 \%$ agarose gels containing $1 \mathrm{mg} / \mathrm{mL}$ ethidium bromide, and photographed under UV light. DNA from strains with known NIV, 3-ADON, and 15-ADON genotypes were used as positive controls.

\section{Trichothecene chemotype determination}

Toxin analysis was performed as described by Reynoso et al. (2011). Briefly, $F$. graminearum strains were cultured in Erlenmeyer flasks $(250 \mathrm{~mL})$ containing $25 \mathrm{~g}$ sterilized rice and $10 \mathrm{~mL}$ sterile distilled water. These inoculated flasks were incubated for 28 days at $25^{\circ} \mathrm{C}$ in the dark. Each sample was finely ground in a laboratory grinder and then homogenized. A sub-sample of ground rice $(15 \mathrm{~g})$ was extracted by mixing with $40 \mathrm{~mL}$ acetonitrile:methanol $(14: 1, \mathrm{v} / \mathrm{v})$, shaken for $2 \mathrm{~h}$ on an oscillatory shaker $(150 \mathrm{rpm})$, and then filtered through Whatman No. 1 filter paper. A syringe ( $3 \mathrm{~mL}$ capacity) plugged with glass wool and dry-packed with alumina:carbon (20:1, w/w; $0.5 \mathrm{~g}$ ) was used as a mini-cleanup column. A 2-mL aliquot of extract was applied to the column, allowed to drain under gravity, and the column was washed with $500 \mu \mathrm{L}$ acetonitrile:methanol:water $(80: 5: 15, v / v / v)$, and the eluate were evaporated to dryness. The cleaned-up residue was dissolved in $500 \mu \mathrm{L}$ toluene:acetonitrile $(5: 95, \mathrm{v} / \mathrm{v})$. The standard mycotoxins and the extracts were applied to TLC plates (Merck 5553, Merck KGaA, Darmstadt, Germany), and the extracts were resolved in a solvent system containing chloroform:acetone:2-propanol $(8: 1: 1, \mathrm{v} / \mathrm{v} / \mathrm{v})$ until they reach $1 \mathrm{~cm}$ from the top of the plate. Plates were developed by spraying with $20 \%$ aluminum chloride in ethanol and heating to $120^{\circ} \mathrm{C}$ for $7 \mathrm{~min}$. The presence of DON, NIV, 3-ADON, and 15-ADON production was determined by visual comparison with known amounts of standards illuminated with UV light at 366 $\mathrm{nm}$ (Trilogy Analytical Laboratory Inc., Washington, MO, USA).

\section{RESULTS}

\section{Identification of $F$. graminearum isolates}

In total, 103 F. graminearum isolates were obtained; 23 from Rio Negro, 19 from Flores, 25 from Colonia, and 36 from Soriano. All isolates produced a fragment of 400 bp in the PCR amplification with $\mathrm{Fg} 16 \mathrm{~F} / \mathrm{R}$ primers, confirming that all belonged to F. graminearum.

\section{Population genetic analyses}

A total of 172 AFLP bands were identified in the 200-600 bp range from the 103 analyzed isolates when using the three primer pair combinations. Of these 172 AFLP loci, 154 were polymorphic (89.5\% overall). The percentage of polymorphic loci in each population is shown in Table 1. The primer combinations EcoRI + CC and Msel + CG resulted in 45 amplified bands, the combination of EcoRI + TG and Msel + TT resulted in 79 amplified bands, and EcoRI + AA and Msel + AT resulted in 27 amplified bands. All isolates had AFLP profiles typical of F. graminearum s.s. (lineage 7). No strains with the same AFLP haplotype (clones) were found in different populations. Normalized G was high (100\% of the count) in all four populations (Table 1). For the full set of 
172 loci, the average $h$ was 0.180 among all isolates, 0.175 for the isolates from Flores, 0.159 for the isolates from Soriano, 0.172 for the isolates from Rio Negro, and 0.167 for the isolates from Colonia (Table 1). The estimates $G_{\mathrm{ST}}$ and $N_{\mathrm{m}}$, determined from the AFLP data, demonstrated low genetic differentiation and high gene flow among the populations (Table 2). The mean $G_{\mathrm{ST}}$ (fixation index or differentiation among populations due to population subdivision) across all 172 loci was 0.072 with $P=0.652$, indicating that the allele frequencies are similar in all four populations (Table $2)$. The lowest $G_{S T}$ value was between Soriano and Colonia $(0.036, P=0.371)$ and the highest was between Flores and Rio Negro $(0.057, \mathrm{P}=0.801)$ (Table 2). The gene flow ranged from 8.24 between Flores and Rio Negro to 13.3 between Soriano and Colonia (Table 2). Pairwise comparisons of Nei's unbiased genetic identity and genetic distance among the four populations were uniformly high (ranging from 0.987 to 0.990 ) and uniformly low (ranging from 0.007 to 0.013 ) (Table 2). The AMOVA indicated that $99 \%$ of the variation recorded occurred within populations whereas only $1 \%$ of the variation occurred between populations.

For the calculation of the two-locus linkage disequilibrium in F. graminearum populations, there were a total of 14,706 possible pair-wise comparisons for the 172 AFLP loci. We rejected the null hypothesis of two-locus linkage equilibrium $(P<0.01)$ in favor of the alternative hypothesis of two-locus LD for 768 pairs of loci $(5.2 \%)$ from the Flores population, 360 pairs of loci $(2.4 \%)$ from the Soriano population, 616 pairs of loci $(4.2 \%)$ from the Rio Negro population, 480 pairs of loci $(3.3 \%)$ from the Colonia population, and 2040 pairs of loci $(13.9 \%)$ from the combined population. At the $\mathrm{P}<0.05$ significance level, we rejected the null hypothesis of two-locus linkage equilibrium for 1996 pairs of loci (13.6\%) from the Flores population, 1684 pairs of loci (11.4\%) from the Soriano population, 800 pairs of loci (5.4\%) from the Rio Negro population, and 1448 pairs of loci $(9.8 \%)$ from the Colonia population. Very low multilocus LD (LD $=0.02$ to 0.04 ) was observed in all populations, which were all significantly different from the expectation of random mating $(\mathrm{P}<$ 0.01 in all cases) (Table 1).

Table 1. Estimates of genotypic diversity (G), genetic diversity $(h)$, and multilocus linkage disequilibrium (LD) in four Uruguayan populations of Fusarium graminearum based on AFLP loci.

\begin{tabular}{l|c|c|c|c|c|c|c}
\hline Population & $\begin{array}{c}\text { No. of } \\
\text { isolates }\end{array}$ & $\begin{array}{c}\text { No. of } \\
\text { haplotypes }\end{array}$ & $\begin{array}{c}\text { Genotypic diversity } \\
(\hat{\mathrm{G}})^{\mathrm{a}}\end{array}$ & $\begin{array}{c}\text { Normalised genotypic } \\
\text { diversity }(\hat{\mathrm{G}} / \mathrm{n})^{\mathrm{b}}\end{array}$ & $\begin{array}{c}\text { Polymorphic } \\
\text { loci (\%) }\end{array}$ & $h$ & Multilocus LD (P) \\
\hline Flores & 19 & 19 & 19 & 1 & 55.8 & 0.175 & $0.04(<0.01)$ \\
\hline Soriano & 36 & 36 & 36 & 1 & 44.2 & 0.159 & $0.03(<0.01)$ \\
\hline Río Negro & 23 & 23 & 23 & 1 & 52.3 & 0.172 & $0.03(<0.01)$ \\
\hline Colonia & 25 & 25 & 25 & 1 & 51.2 & 0.167 & $0.02(<0.01)$ \\
\hline
\end{tabular}

${ }^{a}$ Calculated as described by Milgroom (1996) for comparisons of AFLP allelic data at 172 loci. ${ }^{b}$ Calculated by dividing ( $\hat{\mathrm{G}})$ by the number of AFLP haplotypes observed in each population.

Table 2. Pairwise calculations of gene flow $\left(N_{\mathrm{m}}\right)$ (above diagonal) and fixation index $\left(G_{\mathrm{ST}}\right)$ (below diagonal) based on 172 loci AFLP loci for four Uruguayan populations of Fusarium graminearum.

\begin{tabular}{l|c|c|c|c}
\hline Populations & Flores & Soriano & Río Negro & Colonia \\
\hline Flores & - & 10.14 & 8.24 & 10.10 \\
\hline Soriano & 0.047 & - & 8.83 & 13.31 \\
\hline Río Negro & 0.057 & 0.054 & - & 9.04 \\
\hline Colonia & 0.047 & 0.036 & 0.052 & - \\
\hline
\end{tabular}

\section{Trichothecene determination by PCR and chemical analyses}

Trichothecene mycotoxin genotypes were determined for all 103 isolates of $F$. graminearum 
s.s., and we found that with 102 had the 15-ADON genotype whereas only one isolate from the Flores population had the NIV genotype. The chemical analysis demonstrated that among the group of 102 isolates genetically identified as 15-ADON, all were confirmed to be DON producers, but only 41 strains were also found to be 15-ADON producers. The isolate with the NIV genotype did not produce any toxin.

\section{DISCUSSION}

This study is the first report on the genetic structure of F. graminearum s.s. populations isolated from Uruguay. Previous studies were done on species identity, but the genetic diversity of the strains was not examined. All isolates identified in this analysis could be grouped with standards of $F$. graminearum s.s., which is consistent with previous evidence that this species is the most widespread of the FGSC in South America, North America, and Europe (Tóth et al., 2005; Ramírez et al., 2007; Ward et al., 2008; Alvarez et al., 2011; Astolfi et al., 2012).

The normalized genotypic diversity $\hat{G}$ was high (100\%) in all four populations analyzed. The high genotypic diversity with no clones strongly suggests that sexual reproduction occurs regularly and has a significant role in the population structure of F. graminearum in Uruguay. These results are consistent with populations of F. graminearum from other parts of the world. Additionally, Miedaner et al. (2008) found that populations of F. graminearum from three continents showed haplotype diversity ranges from 60 to $100 \%$, even within populations from individual fields. Moreover, over $90 \%$ of the variation was found within populations, even when samples were collected from areas as small as $0.25 \mathrm{~m}^{2}$.

Low values of $G_{\mathrm{ST}}$ (combined value of 0.072 ) and high values of $\mathrm{Nm}$ (combined value of 6.46) also support the hypothesis that there is significant genetic exchange and minimal geographic subdivision among the four populations. Low levels of $G_{\mathrm{ST}}$ have previously been reported for populations of F. graminearum and other plant-pathogenic fungi (Linde et al., 2002; Ramírez et al., 2007).

The low levels of LD found in these populations imply that outcrossing is common, and that the populations have not experienced a recent bottleneck or invasion. Frequent recombination and high gene flow found here suggest that new traits such as fungicide resistance, aggressiveness, or new toxin profiles could be assimilated rapidly. Voss et al. (2010) showed that progeny of highly aggressive parents might exhibit increased aggressiveness due to recombination, and may therefore adapt nonspecifically to increased quantitative host resistance. Moreover, the number of transgressive segregants largely increases among progeny of low or moderately aggressive parents. Along these lines, Umpiérrez-Failache et al. (2013) showed that all isolates of the FGSC from wheat in Uruguay were capable of inducing FHB at $21 \mathrm{dpi}$; however, variation in aggressiveness was observed (5.6 to $27.5 \%$ ). In accordance with the high diversity found within the populations of $F$. graminearum s.s., it can be assumed that recombination alone may suffice to increase aggressiveness in field populations.

The dominant trichothecene genotype in the populations analyzed herein was 15-ADON, which is consistent with results from earlier studies of strains from Uruguay (Pan et al., 2013; Umpiérrez-Failache et al., 2013) and with previous analyses of F. graminearum s.s. isolates from wheat in Brazil (Astolfi et al., 2012). In Argentina, although 15-ADON seems to dominate among F. graminearum s.s. isolates, a DON/NIV genotype/chemotype has also been found in wheat and barley. The DON/NIV genotype seems to occur at very low frequencies in populations of $F$. graminearum and its chemical phenotype was either DON or NIV (Reynoso et al., 2011; Castañares et al., 2014). Nevertheless, the DON/NIV genotype was not detected in the current study. Also, 
the special interest in the rare NIV genotype is because NIV is more toxic than DON in most animal systems (van der Lee et al., 2015). The validation of trichothecene genotypes via chemical analyses can help to provide more reliable data on the trichothecene profile of fungal populations. In Uruguay, there is no information on F. graminearum s.s. chemical production profiles of isolates from wheat or other small cereal crops. Therefore, the present study represents the first time that populations of Uruguayan F. graminearum s.s. have been examined by chemical analysis. The chemical analysis showed that $40 \%$ of strains that were found to have the $15-$ ADON genotype produced only DON, revealing a distinction among the group of isolates genetically identified as 15-ADON. This discrepancy between genotype and chemotype has often been reported (de Kuppler et al., 2011; Somma et al., 2014), which is the main reason why the evaluation of possible risks related to $F$. graminearum wheat contamination cannot be based solely on trichothecene genotyping. Therefore, a thorough validation of the trichothecene genotypes by chemical analyses remains important for reporting the frequency of the different chemotypes within a target population. Previous surveys of $F$. graminearum populations have indicated shifts in trichothecene genotype/ chemotype frequencies, possibly due to changes in climate, agricultural practices, regional host composition, and the movement of pathogen populations into new areas. Additionally, phenotypic differences such as increased conidia production, higher growth rates, or increased production of DON could provide fitness advantages in a population resulting in range expansion and significant changes in population frequencies (Ward et al., 2008; Zhang et al., 2012; Aamot et al., 2015). However, this study showed that populations of F. graminearum s.s. from Uruguay are characterized by a high level of homogeneity in the trichothecene profile (DON/15-ADON) and that no potential shifts exist in the populations in contrast to previous studies from Uruguay. This is especially interesting due to the frequent recombination and high gene flow present in the populations of $F$. graminearum analyzed herein, where novel or advantageous pathogenic traits could be assimilated and dispersed rapidly throughout the region. In addition to this, significant NIV genotype populations of $F$. asiaticum were recently detected in wheat in major rice-producing areas of Uruguay (Umpiérrez-Failache et al., 2013). Additional analyses of temporally separate populations are needed to evaluate the impact that this new species may have on F. graminearum populations.

Ward et al. (2002) suggested that increased vigilance of plant control and plant quarantine programs is needed to reduce the risk that FGSC strains with novel toxigenic potential could spread globally. However, knowledge regarding the trichothecene genotypes in each country is still too limited to pursue global control efforts, and hence worldwide maps of the trichothecene genotypes contaminating cereals need to be designed to better evaluate strategies for facing the eventual import/ export of new species/strains with new toxigenic potential. Nevertheless, such genotype profiles must be validated with chemical analyses in order to understand the effective toxin production capability of each FGSC strain (Somma et al., 2014). In this sense, the present study adds to the current world knowledge about this pathogen and expands our understanding about the agroecology of $F$. graminearum as well as the correlation between trichothecene genotypes and chemotypes.

In conclusion, this research provides the first detailed description of the genetic structure of populations of F. graminearum s.s. present in the major wheat-growing region of Uruguay. Our data support the hypothesis that the populations are genotypically diverse, and that a regular, homogenizing gene flow occurs across the wheat-growing region of Uruguay. Additionally, we determined for the first time the potential (genotype) and production profiles of trichothecene among F. graminearum s.s. isolates obtained from wheat grains in Uruguay. These finding have important practical implications for the development of effective management strategies to cope with FHB epidemics and for monitoring any future changes in this fungal pathogen related to 
trichothecene production as it affects a highly economically relevant crop. Therefore, we think that plant-breeding efforts may benefit from the inclusion sionof representatives of most of the $F$. graminearum s.s. species rather than a single genotype when testing new plant varieties for FHB resistance. Further characterization of the isolates identified herein and comparisons with isolates from different years and crops are required to better understand populations of this pathogen and predict future changes.

\section{Conflicts of interest}

The authors declare no conflict of interest.

\section{ACKNOWLEDGMENTS}

We thank Programa de Desarrollo de las Ciencias Básicas (PEDECIBA) for financial support.

\section{REFERENCES}

Aamot H, Ward T, Brodal G, Vraslstad T, et al. (2015). Genetic and phenotypic diversity within the Fusarium graminearum species complex in Norway. Eur. J. Plant Pathol. 142: 501-519. http://dx.doi.org/10.1007/s10658-015-0629-4

Alvarez CL, Somma S, Proctor RH, Stea G, et al. (2011). Genetic diversity in Fusarium graminearum from a major wheatproducing region of Argentina. Toxins (Basel) 3: 1294-1309. http://dx.doi.org/10.3390/toxins3101294

Astolfi P, Reynosos M, Ramirez M, Chulze S, et al. (2012). Genetic population structure and trichothecene genotypes of Fusarium graminearum isolated from wheat in southern Brazil. Plant Pathol. 61: 289-295. http://dx.doi.org/10.1111/j.13653059.2011.02515.x

Castañares E, Albuquerque DR, Dinolfo MI, Pinto VF, et al. (2014). Trichothecene genotypes and production profiles of Fusarium graminearum isolates obtained from barley cultivated in Argentina. Int. J. Food Microbiol. 179: 57-63. http:// dx.doi.org/10.1016/j.jijfoodmicro.2014.03.024

Chandler EA, Simpson DR, Thomsett MA and Nicholson P (2003). Development of PCR assays to Tri7 and Tri13 trichothecene biosynthetic genes, and characterization of chemotypes of Fusarium graminearum, Fusarium culmorum and Fusarium cerealis. Physiol. Mol. Plant Pathol. 62: 355-376. http://dx.doi.org/10.1016/S0885-5765(03)00092-4

de Kuppler AL, Steiner U, Sulyok M, Krska R, et al. (2011). Genotyping and phenotyping of Fusarium graminearum isolates from Germany related to their mycotoxin biosynthesis. Int. J. Food Microbiol. 151: 78-86. http://dx.doi.org/10.1016/j. iifoodmicro.2011.08.006

Desjardins AE and Proctor RH (2011). Genetic diversity and trichothecene chemotypes of the Fusarium graminearum clade isolated from maize in Nepal and identification of a putative new lineage. Fungal Biol. 115: 38-48. http://dx.doi. org/10.1016/j.funbio.2010.10.002

Desjardins AE (2008). Natural product chemistry meets genetics: when is a genotype a chemotype? J. Agric. Food Chem. 56 : 7587-7592. http://dx.doi.org/10.1021/jf801239j

Green M and Sambrook J (2012). Molecular cloning: A laboratory Manual. 4th edn. Cold Spring Harbor Laboratory Press, New York.

Guo XW, Fernando W and Seow-Brock H (2008). Population structure, chemotype diversity, and potential chemotype shifting of Fusarium graminearum in wheat fields of Manitoba. Plant Dis. 92: 756-762. http://dx.doi.org/10.1094/PDIS-92-5-0756

Lee S and Taylor J (1990). Isolation of DNA from fungal mycelia and single spores. In: PCR protocols: a guide to methods and applications (Gelfand M, Snindky D and White J, eds.). Academic Press, San Diego, 282-287.

Leslie J and Summerell B (2006). The Fusarium Laboratory Manual. Blackwell Publishing, Australia.

Linde CC, Zhan J and McDonald BA (2002). Population structure of Mycosphaerella graminicola: from lesions to continents. Phytopathology 92: 946-955. http://dx.doi.org/10.1094/PHYTO.2002.92.9.946

Marasas W, Nelson P and Toussoun T (1984) Toxigenic Fusarium species. Identity and mycotoxicology. The Pennsylvania State University Press, University Park, PA and London, England, 328.

McDermontt J and McDonald B (1993). Gene flow in plant pathosystem. Annu. Rev. Phytopathol. 31: 353-373. http://dx.doi. org/10.1146/annurev.py.31.090193.002033 
Miedaner T, Cumagun C and Chakraborty S (2008). Populations genetics of three important head blight pathogens Fusarium graminearum, F. pseudograminearum and F. culmorum. J. Pathol. 156: 129-139.

Milgroom MG (1996). Recombination and the multilocus structure of fungal populations. Annu. Rev. Phytopathol. 34: $457-477$. http://dx.doi.org/10.1146/annurev.phyto.34.1.457

MSP (2001). Decreto No 533/001 para la toxina deoxinivalenol (DON). Ministerio de Salud Pública, Uruguay.

Nei M (1973). Analysis of gene diversity in subdivided populations. Proc. Natl. Acad. Sci. USA 70: 3321-3323. http://dx.doi. org/10.1073/pnas.70.12.3321

Nei M (1978). Estimation of average heterozygosity and genetic distance from a small number of individuals. Genetics 89 : 583-590.

Nicholson P, Simpson D, Weston G, Rezanoor H, et al. (1998). Detection and quantification of Fusarium culmorum and Fusarium graminearum in cereals by using PCR assays. Physiol. Mol. Plant Pathol. 53: 17-37. http://dx.doi.org/10.1006/ pmpp.1998.0170

Pan D, Graneri J and Bettucci L (2009). Correlation of rainfall and levels of deoxynivalenol in wheat from Uruguay, $1997-2003$. Food Addit. Contam. Part B Surveill. 2: 162-165. http://dx.doi.org/10.1080/02652030903213886

Pan D, Calero N, Mionetto A and Bettucci L (2013). Trichothecene genotypes of Fusarium graminearum from wheat in Uruguay. Int. J. Food Microbiol. 162: 120-123. http://dx.doi.org/10.1016/j.ijfoodmicro.2013.01.002

Qu B, Li HP, Zhang JB, Huang T, et al. (2008). Geographic distribution and genetic diversity of Fusarium gramineraum and $F$. asiaticum on wheat spikes throughout China. Plant Pathol. 57: 15-24.

Quarta A, Mita G, Haidukowski M, Logrieco A, et al. (2006). Multiplex PCR assay for the identification of nivalenol, 3- and 15-acetyl-deoxynivalenol chemotypes in Fusarium. FEMS Microbiol. Lett. 259: 7-13. http://dx.doi.org/10.1111/j.15746968.2006.00235.x

Ramírez ML, Reynoso MM, Farnochi MC, Torres AM, et al. (2007). Population genetic structure of Gibberella zeae isolated from wheat in Argentina. Food Addit. Contam. 24: 1115-1120. http://dx.doi.org/10.1080/02652030701546487

Reynoso MM, Ramirez ML, Torres AM and Chulze SN (2011). Trichothecene genotypes and chemotypes in Fusarium graminearum strains isolated from wheat in Argentina. Int. J. Food Microbiol. 145: 444-448. http://dx.doi.org/10.1016/j. ijfoodmicro.2011.01.020

Somma S, Petruzzella A, Logrieco A, Meca G, et al. (2014). Phylogenetic analyses of Fusarium graminearum strains from cereals in Italy, and characterization of their molecular and chemicals chemotypes. Crop Pasture Sci. 65: 52-60.

Stack R (2000). Return of an old problem: Fusarium head blight of small grains. Plant Health Prog. http://dx.doi.org/10.1094/ PHP-2000-0622-01-RV

Tóth B, Mesterházy A, Horváth Z, Bartók T, et al. (2005). Genetic variability of central European isolates of the Fusarium graminearum species complex. Eur. J. Plant Pathol. 113: 35-45. http://dx.doi.org/10.1007/s10658-005-0296-y

Umpiérrez-Failache M, Garmendia G, Pereyra S, Rodríguez-Haralambides A, et al. (2013). Regional differences in species composition and toxigenic potential among Fusarium head blight isolates from Uruguay indicate a risk of nivalenol contamination in new wheat production areas. Int. J. Food Microbiol. 166: 135-140. http://dx.doi.org/10.1016/j. ijfoodmicro.2013.06.029

van der Lee T, Zhang H, van Diepeningen A and Waalwijk C (2015). Biogeography of Fusarium graminearum species complex and chemotypes: a review. Food Addit. Contam. Part A Chem. Anal. Control Expo. Risk Assess. 32: 453-460. http://dx.doi. org/10.1080/19440049.2014.984244

Vos P, Hogers R, Bleeker M, Reijans M, et al. (1995). AFLP: a new technique for DNA fingerprinting. Nucleic Acids Res. 23: 4407-4414. http://dx.doi.org/10.1093/nar/23.21.4407

Voss HH, Bowden RL, Leslie JF and Miedaner T (2010). Variation and transgression of aggressiveness among two Gibberella zeae crosses developed from highly aggressive parental isolates. Phytopathology 100: 904-912. http://dx.doi.org/10.1094/ PHYTO-100-9-0904

Ward TJ, Bielawski JP, Kistler HC, Sullivan E, et al. (2002). Ancestral polymorphism and adaptive evolution in the trichothecene mycotoxin gene cluster of phytopathogenic Fusarium. Proc. Natl. Acad. Sci. U. S. A. 99: 9278-9283. http://dx.doi. org/10.1073/pnas.142307199

Ward TJ, Clear RM, Rooney AP, O'Donnell K, et al. (2008). An adaptive evolutionary shift in Fusarium head blight pathogen populations is driving the rapid spread of more toxigenic Fusarium graminearum in North America. Fungal Genet. Biol. 45: 473-484. http://dx.doi.org/10.1016/j.fgb.2007.10.003

Weir BS (1979). Inferences about linkage disequilibrium. Biometrics 35: 235-254. http://dx.doi.org/10.2307/2529947

Zeller KA, Bowden RL and Leslie JF (2003). Diversity of epidemic populations of Gibberella zeae from small quadrants in Kansas and North Dakota. Phytopathology 93: 874-880. http://dx.doi.org/10.1094/PHYTO.2003.93.7.874

Zhang H, Van der Lee T, Waalwijk C, Chen W, et al. (2012). Population analysis of the Fusarium graminearum species complex from wheat in China show a shift to more aggressive isolates. PLoS One 7: e31722. http://dx.doi.org/10.1371/journal. pone. 0031722 